\title{
Effect of Blended Learning Classroom Environment on Student's Satisfaction
}

\author{
Shojae Aldin Kalantarrashidi ${ }^{1}$, Ebrahim Mohammadpour ${ }^{2}$, Faranak Sahraei ${ }^{3}$ \\ ${ }^{1}$ Farhangian University, Rasoule Akram Campus of Khuzestan, Iran \\ ${ }^{2}$ Farhangian University, Shahid Modarress Campus of Kurdistan, Iran \\ ${ }^{3}$ Educational Administration (MA) \\ Correspondence: Shojae Aldin Kalantarrashidi, Farhangian University, Rasoule Akram Campus of Khuzestan, Iran
}

Received: June 1, 2015 Accepted: June 19, 2015 Online Published: August 7, 2015

doi:10.11114/jets.v3i5.1013 URL: http://dx.doi.org/10.11114/jets.v3i5.1013

\begin{abstract}
This study investigates the impact of blended learning classroom environment on students' satisfaction. The study was carried out in Farhangian University, College of Hazrate Fatemah, Khuzestan Iran, for undergraduate students who were studying in the field of primary education. To examine the level of students' satisfaction, after undergoing blended learning, a questionnaire and interview form were prepared. The data obtained from students' responses to the questionnaire and the interview form from different groups of blended learning environment, namely high technology dominant, balance technology and face to face, and face to face dominant. Descriptive statistic indices were used to describe the data. The results indicate that students' satisfaction in the balance technology and face to face classroom environment was higher than that of the other two classroom environments. That is, students were more satisfied with balance technology and face to face than the other two classes. In addition, the students were preferred to take more courses in a balance technology and face to face classroom environment compared to other two classroom environments.
\end{abstract}

Keywords: blended learning, classroom environment, educational technology, Iran, students' satisfaction

\section{Introduction}

Traditional learning and e-learning approaches alone may not be effective enough in achieving learning objectives (Singh, 2003; Goolnik, 2006). In contrast, in blended learning (BL) classroom environments in which traditional and e-learning settings are combined hold great promises in education. The combination of these two is better than traditional and e-learning technology (Singh, 2003). There is evidence showing that BL outperform both face-to-face (F2F) and online learning (Nagel, 2009). More and more students are enrolling in BL courses because it is offerings transcend the boundaries of time and space, creating new opportunities for students, faculty, and educational institutions (Mayadas, John, \& Paul, 2009). It has been predicted that BL courses will soon become an established method of teaching in most colleges and universities and that soon the majority of students will take at least some of their courses under BL environment (Nagel, 2009). BL provides instructors and learners with both F2F and e-learning environments (Garrison \& Vaughan, 2008; Graham, 2006; Mortera-Gutierrez, 2006; Shemla \& Nachmias, 2007) and it benefits both instructors and learners (Kirkley \& Kirkley, 2005; Picciano, 2006). Suggested that instructors endeavor to find the best combination of BL because they can apply the best pedagogical techniques of online and face-to-face learning.

One of the challenges of $\mathrm{BL}$ is to find a balanced combination of a synchronized instruction and F2F collaboration (Driscoll, 2002; Bersin, 2004). One of the significant aspects of a balanced combination is the ability to redesign a better $\mathrm{BL}$ course. The other important challenge in this regard is to find out how much and to what extent F2F and technology can be mixed. In other words, it should be determined that what percentage of a BL should be online and what percentage F2F. The number of F2F and online sessions varies from course to course (Allen \& Seaman, 2007). Allen and Seaman (2007) quantified a blended course as that between $30 \%$ and $70 \%$ of the course content is provided online, while an online course is featured with at least $70 \%$ of the course content delivered online. There are several experimental studies that show the share of the F2F and online learning separately in a BL class (Osguthrope \& Graham, 2006; Driscoll, 2002; Bersin, 2004). In fact, there is no study that specifically deals with how much of the class time should be allocated to the technology and how much to the F2F learning in a BL method. In fact, it is a concern to find out how the level of students' 
satisfaction between the three groups, namely high technology dominant (HTD), balance teaching and F2F (BT\&F2FD), and high F2F dominant (HF2FD) in BL classrooms cause learning and which one is more effective is not answered yet.

The next challenge is the level of students' satisfaction after their grouping. Nowadays, several countries including Iran have taken the BL as a new way of learning. One of the main reasons is to find the new role played by students and instructors under the new educational setting (Zamani Manesh, Khorasani, and Bagher Abadi Gh, 2012). The researchers support Montazer, \& Bahreininejad, 2012).idea that the perceptions of four important parties (students, instructors, educational managers and content) affect the BL setting and these perceptions need to be identified.

Although studies have uncovered a number of advantages in implementing BL, insufficient learning satisfaction has long been a challenge ahead of successful experience by the new educational approach (So, \& Brush, 2008). Students' satisfaction is the student's perceived value of his or her educational experiences at an educational institution (Astin, 1993). There are different views about the effects of using technology or F2F in the classroom activity. Several studies have argued that balance classes (online and F2F) create better learning opportunity for students than online or F2F (Alebaikan \& Troudi, 2010; Bersin, 2004). Furthermore, some other works have maintained that students under online teaching environment are significantly more positive in their evaluations (Kleinman \& Entin, 2002; Lim, \& Morris, 2009) pointed out that students are more satisfied under blended learning settings. Some researchers have shown that high technology (online class) brings in more students' satisfaction (Wong \& Tatnall, 2009; Allen \& Seaman, 2004). In contrast, there are also studies that have demonstrated no significant difference between the delivery modes of instruction (Bernard et al., 2004; McFarland \& Hamilton, 2005; Zhang, Zhao, Zhou, \& Nunamaker, 2004). Moreover, others demonstrated that students enrolled in online classes are less satisfied with their course experiences in compare with those in traditional F2F class settings (Priluck, 2004; Tallent et al., 2006).

As mentioned earlier, the level of students' satisfaction regarding courses plays a dominant role in effectiveness evaluation of blended learning. At any level, there is a paucity of studies on the differences in students' satisfaction between blended and traditional learning and in the physical education area in particular. Unfortunately, there are only few works conducted in this area in Iran. Therefore, the present study tries to examine the perceptions of these actors who deal with BL courses in the selected online content. Hence, this study is designed to investigate the impact of BL environment on students' satisfaction. There is a necessity to examine students' satisfaction towards different components of learning environment. These components in the present study are the subject or course content, teaching and learning approach, instructor, interaction, and technology.

\section{Methodology}

This study is a quasi-experiment research. Since BL is defined as a continuum from low to high technologies; three different groups of BL were defined to examine the impact of each BL on students' satisfaction. Table 1 presents the properties of the groups.

Table 1. The properties of BL groups

\begin{tabular}{lccc}
\hline Groups & $\begin{array}{c}\text { High technology } \\
\text { dominant (HTD) }\end{array}$ & $\begin{array}{c}\text { Balance technology and } \\
\text { F2F (BT\&F2FD) }\end{array}$ & $\begin{array}{c}\text { High F2F dominant } \\
\text { (HF2FD) }\end{array}$ \\
\cline { 2 - 5 } & $\begin{array}{c}\text { Features 70\% online and 30\% F2F } \\
\text { instruction }\end{array}$ & $\begin{array}{c}\text { F2F and 50\% online } \\
\text { instruction }\end{array}$ & $\begin{array}{c}\text { 70\% F2F and 30\% online } \\
\text { instruction }\end{array}$ \\
\hline
\end{tabular}

\subsection{Sample and Sampling Method}

The study was conducted at Farhangian University, College of Hazrate Fatemah, Khuzestan Iran in the second semester of 2012-2013 academic year. The collage is located at Ahwaz the center of Khuzestan province. The university has two colleges of male and female. Each college consists of three faculties Science, Education, and Language and Literature. According to the last statistics in 2012, the total number of students in the university were 2450, (1250 at the male college and 1200 at the female college) who were studying in primary education, technical education, Islamic education, chemistry education, counseling, biology education, English language, social science, physics education, Persian literature, and mathematics education.

The following steps undertook to the selection of population and sample of the study. First, of these two colleges, the female college was selected purposively, because the female college had more classes and consequently more appropriate to conduct the study. Second, of all the study majors, mentioned above, primary education field is selected because it was the only field which had five classes, while all other study fields had two or three classes only. Third, of five primary education classes, three classes in which the "new method of teaching and learning subject" is taught by the same lecturer was selected. This facilitated the researcher to control the lecturer's characteristics (gender, age, years of teaching experience, teaching style) that might influence the dependent variables (satisfaction). Fourth, of all the subject matters, the "new method of teaching and learning" is selected. The reason for selecting this subject is that students will be teacher after graduation and they will deal with teaching and learning activities. 
The total numbers of students were 84 students ( 28 students per class, on average). The classes were assigned into three different level of BL classroom environment randomly. The duration of the study was one full semester, which was started on December 2012 and ended on May 2013.A semester comprises 16 weeks, 12 of which are the actual studying weeks and the four rests are for registration, mid-term, final exams and semester break.

\subsection{Data}

Measuring students' satisfaction towards BL is the main objective of this study. A questionnaire was developed by the researcher and administered to all the students in the three groups of BL at the end of the treatment (week 11). Each component (course content, teaching and learning approaches, instructor, interaction, and technology) was measured by five questions. Thus, the questionnaire was contained 25, five points rating-scale items to address the students' satisfaction towards BL.

To ensure the validity of the questionnaire with respect to content validity and face validity, the questionnaire was sent to five lectures who have been teaching the "new method of teaching and learning subject" for at least three years. The results indicated that the questionnaire is face valid and its content is relevant to students' satisfaction of BL environment. Besides, Cronbach's alpha was used to estimate the reliability of the questionnaire. A value of 0.86 was obtained which is sufficiently higher than the acceptable limit. Usually, an index of 0.70 is an acceptable value of reliability (Gable, 2003; Kaplan \& Saccuzzo, 2009).

In addition, interview was conducted to support the data were collected through questionnaire and to understand the extent to which BL influenced students' satisfaction across different groups of BL. Thus, a semi-structured interview was developed and used for data collection. To carry out the interview, three students from each group sampled at random (overall nine students) and interviewed by the researcher using the interview form in a comfortable place at the college. The three students from each group of BL were interviewed simultaneously. That is, when a question was asked, all three students expressed their opinions with respect to the question.

To make sure that the interview form is valid and appropriate for collecting the data, the form was sent to another five people (including university and teacher training lecturers in the field of educational technology, primary education, and educational psychology and counseling). Reviewing the comments from all the reviewers revealed that the interview from was appropriate for collection the data on students' satisfaction.

\section{Results}

Table 2 illustrates the mean, standard deviation (SD) and standard error (SE) of students' satisfaction towards BL.

Table 2. Descriptive statistics of students' satisfaction

\begin{tabular}{ccccc}
\hline Groups & $\mathrm{N}$ & Mean & SD & SE \\
\hline HTD & 28 & 3.12 & 0.38 & 0.13 \\
BT\&F2FD & 29 & 4.35 & 0.27 & 0.05 \\
HF2FD & 27 & 3.46 & 0.32 & 0.06 \\
\hline
\end{tabular}

Overall, mean satisfaction of students from balance technology and F2F class towards BL is higher than those students from the other two groups. This was followed by high F2F dominant and high technology dominant, respectively. The SD of the BT\&F2FD group is lower than SD of the other two groups, indicating variation in the measure of satisfaction of this group is lower than the variation in the satisfaction level of HF2FD and HTD groups.

Table 3 portrays students' satisfaction towards BL for all the groups under F2F and online classroom environments.

Table 3. Students' satisfaction towards BL in F2F and online learning situations

\begin{tabular}{|c|c|c|c|c|c|}
\hline \multicolumn{2}{|c|}{ Groups } & $\mathrm{N}$ & Mean & SD & SE \\
\hline \multirow[t]{2}{*}{ HTD } & F2F & \multirow{2}{*}{28} & 2.85 & 0.40 & 0.20 \\
\hline & Online & & 3.38 & 0.35 & 0.06 \\
\hline \multirow{2}{*}{$\mathrm{BT} \& \mathrm{~F} 2 \mathrm{FD}$} & $\mathrm{F} 2 \mathrm{~F}$ & \multirow{2}{*}{29} & 4.32 & 0.29 & 0.05 \\
\hline & Online & & 4.37 & 0.25 & 0.05 \\
\hline \multirow{2}{*}{ HF2FD } & $\mathrm{F} 2 \mathrm{~F}$ & \multirow{2}{*}{27} & 3.57 & 0.35 & 0.07 \\
\hline & Online & & 3.33 & 0.29 & 0.09 \\
\hline
\end{tabular}

Mean satisfaction of students in HTD group towards online learning is slightly higher than F2F. Similarly, mean satisfaction of students in BT\&F2F group towards online learning is slightly higher than F2F. In contrast, mean satisfaction of students in HF2FD group towards F2F learning is higher than online. The SDs indicate that variation in students' satisfaction and it is lower for BT\&F2FD group under online situation across the three groups. 
Table 4 depicts satisfaction of students towards the five components of satisfaction for each group separately.

Table 4. Students' satisfaction towards different components of BL

\begin{tabular}{|c|c|c|c|c|c|}
\hline Group & Component & $\mathrm{N}$ & Mean & SD & SE \\
\hline \multirow{5}{*}{ HTD } & $\mathrm{SCC}$ & \multirow{5}{*}{28} & 2.92 & 0.37 & 0.07 \\
\hline & STLA & & 2.86 & 0.35 & 0.38 \\
\hline & SWINS & & 3.08 & 0.39 & 0.07 \\
\hline & SWINT & & 3.48 & 0.42 & 0.075 \\
\hline & SWT & & 2.75 & 0.36 & 0.07 \\
\hline \multirow{5}{*}{ BT\&F2FD } & SCC & \multirow{5}{*}{29} & 4.30 & 0.30 & 0.05 \\
\hline & STLA & & 4.32 & 0.28 & 0.05 \\
\hline & SWINS & & 4.39 & 0.27 & 0.05 \\
\hline & SWINT & & 4.51 & 0.25 & 0.05 \\
\hline & SWT & & 4.23 & 0.26 & 0.05 \\
\hline \multirow{5}{*}{ HF2FD } & SCC & \multirow{5}{*}{27} & 3.43 & 0.30 & 0.06 \\
\hline & STLA & & 3.44 & 0.31 & 0.06 \\
\hline & SWINS & & 3.18 & 0.34 & 0.07 \\
\hline & SWINT & & 3.44 & 0.37 & 0.07 \\
\hline & SWT & & 3.16 & 0.30 & 0.06 \\
\hline
\end{tabular}

In the HTD group, mean satisfaction to interaction (SWINT) is higher than that of all other components. This was followed by satisfaction to instructor (SWINS), course content (SCC), teaching and learning approaches (STLA) and technology (SWT), respectively. Similarly, in the BT\&F2F group, SWINT was higher than all the other components. This was followed by SWINS, STLA, SCC, and SWT, respectively. In the HF2FD group, SWINT and STLA were equally higher than that of all other components. This was followed by SCC, SWINS, and SWT, in the order mentioned.

Table 5 represents students' satisfaction towards BL in each group under F2F and online learning situations.

Table 5. A comparison of satisfaction towards components in $\mathrm{F} 2 \mathrm{~F}$ and online learning situations

\begin{tabular}{|c|c|c|c|c|c|c|c|c|}
\hline & & & \multicolumn{2}{|c|}{$\mathrm{F} 2 \mathrm{~F}$} & \multicolumn{4}{|c|}{ Online } \\
\hline Group & Component & No & Mean & SD & SE & Mean & SD & $\mathrm{SE}$ \\
\hline \multirow{5}{*}{ HTD } & SCC & \multirow{5}{*}{28} & 2.63 & .43 & .08 & 3.21 & .31 & .06 \\
\hline & STLA & & 2.74 & .37 & .70 & 2.98 & .33 & .06 \\
\hline & SWINS & & 3.07 & .44 & .08 & 3.09 & .33 & .06 \\
\hline & SWINT & & 3.37 & .39 & .07 & 3.59 & .37 & .07 \\
\hline & SWT & & 2.46 & .34 & .06 & 3.03 & .37 & .07 \\
\hline \multirow{5}{*}{ BT\&F2FD } & SCC & \multirow{5}{*}{29} & 4.23 & .36 & .06 & 4.36 & .24 & .04 \\
\hline & STLA & & 4.25 & .28 & .05 & 4.39 & .27 & .05 \\
\hline & SWINS & & 4.37 & .24 & .04 & 4.40 & .30 & .06 \\
\hline & SWINT & & 4.47 & .28 & .05 & 4.54 & .22 & .04 \\
\hline & SWT & & 4.22 & .30 & .06 & 4.24 & .21 & .04 \\
\hline \multirow{5}{*}{ HF2FD } & SCC & \multirow{5}{*}{27} & 3.28 & .31 & .06 & 3.57 & .28 & .05 \\
\hline & STLA & & 3.61 & .36 & .07 & 3.27 & .25 & .05 \\
\hline & SWINS & & 3.34 & .37 & .07 & 3.02 & .30 & .06 \\
\hline & SWINT & & 4.04 & .39 & .07 & 2.84 & .35 & .07 \\
\hline & SWT & & 3.57 & .30 & .06 & 3.95 & .29 & .06 \\
\hline
\end{tabular}

In the HTD group, under both F2F and online learning situations, SWINT was higher than that of all the other components. This was followed by SWINS, STLA, SCC, and SWT under F2F learning situation, respectively. Whereas under online learning situation SCC, SWINS, SWT, and STLA had the higher level of satisfaction, in the order mentioned. In the BT\&F2F group, SWINT, SWINS, STLA, SCC, and SWT had the higher mean of satisfaction both under F2F and online learning situations, respectively. In the HF2FD class, under F2F learning situation, SWINT, STLA, SWT, SWINS, SCC under F2F learning situation and SWT, SCC, STLA, SWINS, SWINT under online learning situation had the higher mean, in the order mentioned.

Table 6 summaries students' satisfaction toward BL under F2F and online learning situations.

Table 6. A summary of students' satisfaction towards BL under F2F and online learning situations

\begin{tabular}{ccccccc}
\hline & \multicolumn{2}{c}{ HTD } & \multicolumn{2}{c}{ BT\&F2FD } & \multicolumn{2}{c}{ HF2FD } \\
\hline Situation & Online & F2F & Online & F2F & Online & F2F \\
Satisfaction & 2.85 & 3.38 & 4.32 & 4.37 & 3.57 & 3.33 \\
\hline
\end{tabular}

Overall, the result shows that balanced technology and F2F had more influence on students' satisfaction towards BL.

Table 7 indicates the overall mean of students' satisfaction and preference towards BL classroom environments. 
Table 7. The overall mean of students' satisfaction

\begin{tabular}{cc}
\hline Group & Satisfaction \\
\hline HTD & 6.23 \\
BT\&F2FD & 8.69 \\
HF2FD & 6.90 \\
\hline
\end{tabular}

\section{Discussion}

The main research question of this study was what combination of blended learning situation is more effective on students' satisfaction. In order to provide an answer to this question, three experimental situations were prepared in which different combinations of technology and F2F were implemented. The results indicates that students' satisfaction was higher in the classroom environment for which a balanced of technology and F2F was applied compare to the other two classroom environments. That is, when a balanced of educational technology (50\%) such as E-mail, Microsoft Word, Power Point presentation, Movies, CD and F2F (50\%) lecturing, question and answer is applied to teach the subject (new method of teaching and learning), the classroom environment had more impact on students' satisfaction towards blended learning in comparison with the other learning situations in which 70\% technology and 30\% F2F and 70\% F2F and 30\% technology is used. This result is consistent with what is obtained from previous studies (Alebaikan \& Troudi, 2010; Bersin, 2004). In addition, the results indicated that the students prefer classroom environment in which a balanced of technology and F2F is applied to teach the subject. It appears that the students in the balance technology and F2F have managed to use the class sitting time. A possible explanation for this result might be due to opportunity that a balanced technology and F2F learning situation provide students with enough time to speak to their lecturer, to ask any possible questions on the course content. It also provides interaction in face to face with lecturer and students and at the same time the online interaction makes students more motivated as they can search in internet for some new knowledge about the course content.

\section{Limitation and Suggestion}

This study encountered some limitations. First, it was carried out in Farhangian University. Other universities can be subject of future works. Second, only girl students participated in the study, and conducing the same study for boys students might yield a different result. Future work may focus on other factors such as students' achievements, students and instructors motivation and attitudes towards blended learning. Results of similar studies on technical fields can be compared with the results or this study. Furthermore, a similar study can be conducted in other countries as well. The role of different cultures on learning experience may also be subject of future studies.

\section{References}

Alebaikan, R., \& Troudi, S. (2010). Blended learning in Saudi universities: challenges and perspectives. Research in Learning Technology, 18(1), 49- 59. http://dx.doi.org/10.1080/09687761003657614

Allen, I. E., \& Seaman, J. (2007). Entering the Mainstream: The Quality and Extent of Online Education in the United States. ERIC.

Astin, A. W. (1993). What matters in college? Four critical years revisited. Jossey- Bass. https://www.researchgate.net/profile/Alexander_Astin/publication.

Bernard, R. M., Abrami, P. C., Lou, Y., Borokhovski, E., Wade, A., Wozney, L., Wallet, P. A., Fiset, M., \& Huang, B. (2004). How does distance education compare with classroom instruction? A meta-analysis of the empirical literature. Review of educational research, 74(3), 379-439. http://dx.doi.org/10.3102/00346543074003379

Bersin, J. (2004). The blended learning book: Best practices, proven methodologies, and lessons learned. John Wiley \& Sons.

Driscoll, M. (2002). Blended learning: Let's get beyond the hype. E-learning, 1(4). Duffy.

Gable, R. K. (2003). Instrument development in the affective domain. Boston: Kluwer.

Garrison, D. R., \& Vaughan, N. D. (2008). Blended learning in higher education: Framework, principles, and guidelines. John Wiley \& Sons.

Goolnik, G. (2006). Effective change management strategies for embedding online learning within higher education and enabling the effective continuing professional development of its academic staff. Turkish Online Journal of Distance Education, 7(1), 9-21.

Graham, C. R. (2006). Blended learning systems. CJ Bonk and CR Graham, The handbook of blended learning: Global perspectives, local designs. Pfeiffer.

Kaplan, R. M., \& Saccuzzo, D. P. (2009). Psychological Testing: Principles, Applications, and Issues (7 ed.): Wadsworth. 
Kirkley, S. E., \& Kirkley, J. R. (2004). Creating next generation blended learning environments using mixed reality,video games and simulations. TechTrends, 49(3), 42-53. http://dx.doi.org/10.1007/BF02763646

Kleinman, J., \& Entin, E. B. (2002). Comparison of in-class and distance-learning students' performance and attitudes in an introductory computer science course. Journal of Computing Sciences in Colleges, 17(6), 206-219.

Lim, D. H., \& Morris, M. L. (2009). Learner and Instructional Factors Influencing Learning Outcomes within a Blended Learning Environment. Educational Technology \& Society, 12(4), 282-293.

Mayadas, A., John, B., \& Paul, B. (2009). Online education today. Science, 323(5910), 85-89. http://dx.doi.org/10.1126/science.1168874

McFarland, D., \& Hamilton, D. (2005). Factors affecting student performance and satisfaction: Online versus traditional course delivery. Journal of Computer Information Systems, 46(2), 25-32.

Montazer, G. A., \& Bahreininejad, A. (2012). An Adaptive and Intelligent Framework for Virtual Higher Education in Iran. International Journal of Information Science and Management (IJISM), 5(1), 11-27.

Mortera-Gutie'rrez, F. (2006). Faculty best practices using blended learning in e- learning and face-to-face instruction. International Journal on E-learning, 5(3), 313.

Nagel, D. (2009). Meta-analysis: Is blended learning most effective. The Journal Newman

Osguthorpe, R. T., \& Graham, C. R. (2006). Blended Learning Environments: Definitions and Directions. Quarterly Review of Distance Education, 4(3), 227-33.

Picciano, A. G. (2006). Blended learning: Implications for growth and access. Journal of asynchronous learning networks, 10(3), 95-102.

Priluck, R. (2004). Web-assisted courses for business education: An examination of two sections of principles of marketing. Journal of Marketing Education, 26(2), 161-173. http://dx.doi.org/10.1177/0273475304265635

Shemla, A., \& Nachmias, R. (2007). Current state of web-supported courses at Tel- Aviv University. International journal on E-Learning, 6(2), 235-246.

Singh, H. (2003). Building effective blended learning programs. EDUCATIONAL TECHNOLOGY-SADDLE BROOK THEN ENGLEWOOD CLIFFS NJ-, 43(6) 51- 54.

So, H. J., \& Brush, T. A. (2008). Student perceptions of collaborative learning, social presence and satisfaction in a blended learning environment: Relationships and critical factors. Computers \& Education, 51(1), 318-336. http://dx.doi.org/10.1016/j.compedu.2007.05.009

Tallent-Runnels, M. K., Thomas, J. A., Lan, W. Y., Cooper, S., Ahern, T. C., Shaw, S., M. \& Liu, X. (2006). Teaching courses online: A review of the research. Review of educational research, 76(1), 93-135. http://dx.doi.org/10.3102/00346543076001093

Wong, L., \& Tatnall, A. (2009). The need to balance the blend: Online versus face-to- face teaching in an introductory accounting subject. Journal of Issues in Informing Science and Information Technology (IISIT), 6, 309-322.

Zamani, M. H., Khorasani, A., \& Bagher, A. G. H. (2012). Effect of using educational, management, executive and motivational solutions on information and communication technology application in medical sciences field. EDCBMJ, 4(4), 203-210.

Zhang, D., Zhao, J. L., Zhou, L., \& Nunamaker, J. F. (2004). Can e-learning replace classroom learning? Communications of the ACM, 47(5), 75-79. http://dx.doi.org/10.1145/986213.986216

This work is licensed under a Creative Commons Attribution 3.0 License. 